УДК 340.13

Т. Е. Ткаченко, Г. В. Шагов

ФГБУВОУ ВО «Академия гражданской защиты МЧС России», e-mail: tkachenko_te@mail.ru

\title{
ПРАВОВЫЕ ОСНОВЫ АКТУАЛЬНОСТИ ПРИМЕНЕНИЯ МАТЕМАТИЧЕСКОГО МОДЕЛИРОВАНИЯ ПРИ ИЗУЧЕНИИ ХАРАКТЕРИСТИК ЗАЩИТНЫХ СООРУЖЕНИЙ ГРАЖДАНСКОЙ ОБОРОНЫ
}

Ключевые слова: правовые основы, правовые документы, нормативно-технические документы, защитные сооружения гражданской обороны, математическое моделирование, система воздухообмена.

В работе рассмотрены основные правовые и нормативно-технические документы, регламентирующие правила эксплуатации защитных сооружений гражданской обороны. Основное внимание уделено нормативно-техническим документам, координирующим мероприятия по поддержанию в удовлетворительном состоянии сами защитные сооружения гражданской обороны и систему воздухообмена в них. Показана возможность применения математического моделирования позволяющего иметь представление о состоянии системы воздухообмена защитных сооружений гражданской обороны в различных режимах.

Мировое развитие на современном этапе характеризуется нестабильностью. Происходит поэтапное перераспределение влияния в пользу новых центров экономического роста и политического притяжения. Наметилась тенденция смещения военных опасностей и угроз в информационное пространство и внутреннюю среду РФ. Наличие потенциально опасных (вредных) факторов природного и техногенного характера. В случае их возникновения высока вероятность массовых потерь в войсках и среди населения, что предопределяет значимость использования средств защиты в комплексе мероприятий гражданской обороны и защиты от чрезвычайных ситуаций $[1,2,3,4]$.

В этих условиях сроки проведения защитных мероприятий могут оказаться крайне ограниченными. Следственно, на первое место должно быть поставлено укрытие населения в защитных сооружениях по месту его пребывания на работе или учебе и в местах постоянного жительства $[8,12]$.

В настоящее время одним из основных способов защиты населения, служат защитные сооружения гражданской обороны (ЗСГО) включающие объекты коллективной защиты (ОКЗ) и средства коллективной защиты (СКЗ) предназначенные для укрытия больших групп людей. С целью защиты их жизни и здоровья от последствий аварий и катастроф на потенциально опасных объектах, либо стихийных бедствий в районах раз- мещения этих объектов, а также от воздействия современных средств поражения (ГОСТ Р.22.0.02-94).

Федеральным законом «О Гражданской обороне» и Постановлением Правительства Российской Федерации «Об утверждении Положения о Гражданской обороне в Российской Федерации» устанавливаются задачи в области гражданской обороны и правовые основы их осуществления, полномочия органов государственной власти Российской Федерации, органов исполнительной власти субъектов Российской Федерации, органов местного самоуправления и организаций независимо от форм собственности, а также силы и средства гражданской обороны $[5,6]$.

Например, по данным Главного управления МЧС России по СанктПетербургу за 2015 года

- обеспеченность Главного управления ЗС ГО составила $100 \%$;

- обеспеченность населения ЗС ГО - $36 \%$;

- количество ЗС ГО, не готовых к приему укрываемых - 47\%;

- количество ЗС ГО, ограниченно готовых к приему укрываемых - $33 \%$;

- количество не достроенных ЗС ГО $-0 \%$;

- спланированных к комплексной проверке ЗС ГО - 81 ед., из них проверено - $100 \%$ [15].

Одним из проблемных вопросов осложняющим применение ОКЗ является состояние их оборудования для очистки 
воздуха. Из-за кризисных явлений в экономике производство этого вида оборудования было прекращено или объемы его производства резко снижены, срок годности регенеративных патронов для регенерации воздуха и фильтров-поглотителей для фильтровентиляционных установок ОКЗ в большинстве случаев истек.

В связи с определенными экономическими трудностями и объективными причинами при проведении научных исследований при изучении характеристик ЗС ГО соискателю необходимо прибегнуть к математическому моделированию, построению эталонных и ситуационных таблиц позволяющих на основе моделирования ситуаций иметь представление об изучаемой характеристике $3 \mathrm{C} \mathrm{ГО,} \mathrm{на-}$ пример, системе воздухообмена.

Целью нашего исследования было создание математической модели, эталонной и ситуационной таблиц, в которых основными исследуемыми ЗСГО компонентами ОКЗ были фильтры-поглотители (ФП) для очистки воздуха от окиси углерода и средства регенерации воздуха.

При работе ОКЗ в режиме вентиляции, когда наружный воздух подается в недостаточном количестве, газовый состав воздуха в нем изменяется - количество $\mathrm{O}_{2}$ уменьшается, а $\mathrm{CO}_{2}$ и водяных паров соответственно увеличивается, концентрация $\mathrm{CO}_{2}$ в таких ситуациях служит показателем наличия загрязнения воздуха продуктами распада белковых веществ.

На одного укрываемого в ОКЗ должно подаваться $2 \mathrm{~m}^{3} /$ ч воздуха, работающего на ПУ $-5 \mathrm{~m}^{3} /$ ч и работающего в фильтровентиляционной камере с электровентилятором - $10 \mathrm{~m}^{3} /$ ч. В 3 -й и 4-й климатических зонах на одного укрываемого объем подаваемого воздуха увеличивается до $10 \mathrm{~m}^{3} / ч$ или применять- ся устройство для охлаждения воздуха. Для очистки воздуха от радиоактивной пыли и отравляющих веществ, подаваемого в ОКЗ, предназначены фильтрыпоглотители типа ФП-50/25, ФП-100/50, ФПУ-200, ФП-200 и ФП-300. В фильтрпоглотитель входит кожух, два перфорированных цилиндра (большой и малый) и центральный цилиндр. Между большим и малым цилиндрами размещается шихта, а между малым и центральным цилиндрами - противоаэрозольный фильтр. Воздух, содержащий радиоактивные, отравляющие, и опасные химические вещества, вначале проходит через противоаэрозольный фильтр, где очищается от твердых и жидких аэрозолей частиц и тумана, затем поступает в шихту, в которой очищается от веществ, находящихся в паро- или газообразном состоянии. Предназначенный для очистки воздуха подаваемого в объекты от радиоактивной пыли и отравляющих веществ фильтр-поглотитель ФП-300, может эксплуатироваться при температуре окружающего и входящего в объект воздуха от -50 до $+50^{\circ} \mathrm{C}$ и относительной влажности воздуха до 95\%. В табл. 1 показана периодичность осмотров и сроки проверки качественного состояния ФП.

Из табл. 1 видно, что плановые проверки состояния ФП через два года позволяют при удовлетворительном их применении и состоянии продлевать сроки использования ФП-100, ФПУ200 до 20 лет с последующей контрольной проверкой через 5 лет, а ФП-300 до 10 лет с последующей контрольной проверкой через 5 лет. Использование ФП-100, ФПУ-200 после хранения 20 лет, ФП-300 после хранения 10 лет не желательно из-за морального и физического износа. Технические характеристики средств очистки воздуха приведены в табл. 2.

Таблица 1

Периодичность и сроки проверки состояния ФП

\begin{tabular}{|l|l|l|}
\hline \multicolumn{1}{|c|}{$\begin{array}{c}\text { Наименование фильтров } \\
\text { поглотителей }\end{array}$} & \multicolumn{1}{|c|}{ Технический осмотр } & \multicolumn{1}{|c|}{ Контрольная проверка } \\
\hline ФП-100, ФПУ-200 & $\begin{array}{l}\text { Через 2 года (после 20 лет - } \\
\text { ежегодно) }\end{array}$ & $\begin{array}{l}\text { Через 5 лет (после 20 лет - че- } \\
\text { ре3 3 года) }\end{array}$ \\
\hline ФП-300 & $\begin{array}{l}\text { Чере3 2 года (после } 10 \text { лет - } \\
\text { ежегодно) }\end{array}$ & $\begin{array}{l}\text { Чере3 5 лет (после } 10 \text { лет - че- } \\
\text { ре3 3 года) }\end{array}$ \\
\hline
\end{tabular}


Технические характеристики средств очистки воздуха

\begin{tabular}{|c|c|c|c|c|}
\hline Средство очистки & $\begin{array}{c}\text { Производитель- } \\
\text { ность, } \mathrm{M}^{3} / \text { ч }\end{array}$ & $\begin{array}{c}\text { Сопротивление, } \\
\text { мм вод. ст. }\end{array}$ & Масса, кг & $\begin{array}{c}\text { Габаритные раз- } \\
\text { меры, мм }\end{array}$ \\
\hline$\Phi П-50 / 25$ & 50 & 65 & 15,5 & $325 \times 360$ \\
\hline$\Phi П У-200$ & 100 & По ТУ* & & $407 \times 455$ \\
\hline ФП-200 & 100 & 55 & 31 & $550 \times 580$ \\
\hline$\Phi П-300$ & 300 & 85 & 66 & $332 \times 224$ \\
\hline$\Phi Э-100$ & 100 & 130 & 11 & $355 \times 305$ \\
\hline ФЭ-200 & 200 & 160 & 60 & $610 \times 580$ \\
\hline ФЭ-500 & 500 & 90 & 40 & $400 \times 450$ \\
\hline
\end{tabular}

Пр и м е ч а и е . *По техническим условиям завода-изготовителя.

Например, при размерах $550 \times 580$ мм и массой 66 кг производительность у ФП-300 составляет $300 \mathrm{~m}^{3} / \mathrm{ч}$, а ФП200 при размерах $407 \times 455$ мм и массой 31 кг у ФП-300 производительность $100 \mathrm{~m}^{3} /$ ч, что дает возможность использовать в ОКЗ с разным объемом воздуха ФП разной производительности.

В соответствии с требованиями к эксплуатации ОКЗ $[9,12]$ на первом этапе проводилось определение количества воздуха подаваемого в ОКЗ согласно производительности вентиляторов, проведенные замеры значений работы вентиляторов соответствовали или были не менее значений указанных на графике (рисунок) или значений определяемых по следующим формулам:

Определение подпора воздуха в ОКЗ с обычной герметичностью проводилось по формуле:

$$
\Delta P \geq 137,3\left(\frac{L}{F}\right)^{1,6},
$$

где $\Delta P$ - подпор воздуха в убежище, Па.

Определение подпора воздуха в ОКЗ с повышенной герметичностью проводилось по формуле:

$$
\Delta P \geq 119,6\left(\frac{L}{F}\right)^{2}+194,2 \frac{L}{F},
$$

где $L$ - воздухоподача приточной системы вентиляции, м ${ }^{3} /$ ч; $F$ - площадь ограждений по внутреннему контуру герметизации, $\mathrm{m}^{2}$.

По результатам замеров подпора воздуха не соответствующих величи- нам показанных на графике или формулам (1) и (2) рекомендовалось выявление и устранение мест повышенной утечки воздуха из ОКЗ.

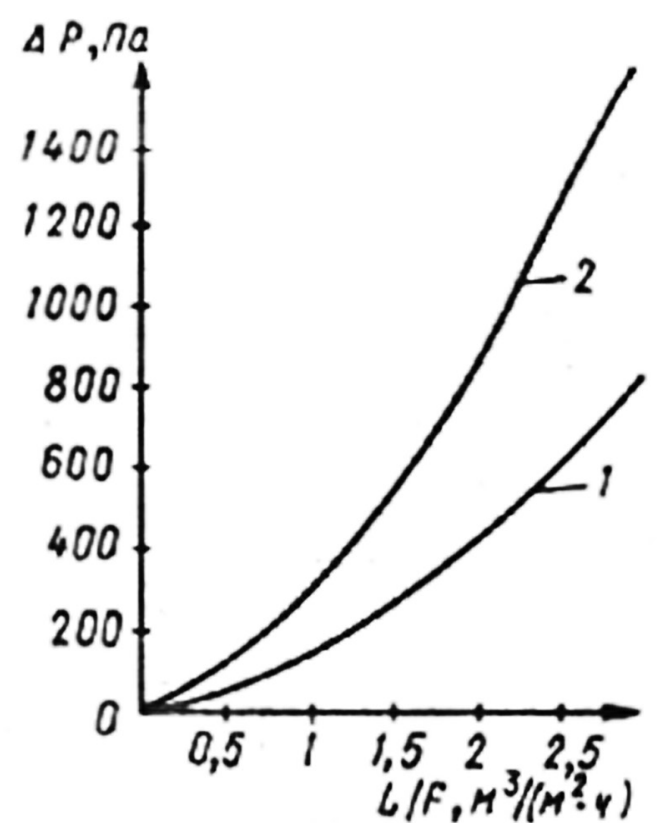

График для оченки герметичности убежищ: 1 - нормативная кривая подпора воздуха в убежсищах с обычной герметичностью; 2 - нормативная кривая подпора воздуха в убежищах с повышенной герметичностью

Следующим этапом была проверка систем воздухоснабжения на способность поддержания нормируемых величин избыточного давления (подпора) воздуха при режимах II и III в следующей последовательности:

- вначале включалась система приточной вентиляции режима II и система 
вытяжной вентиляции, открытыми были соответствующие герметические клапаны, а свободными клапаны-перетекания. В помещении ОКЗ величина подпора воздуха должна была составлять не менее 50 Па;

- затем включалась система поддержания подпора воздуха режима III.

Остальные вентиляционные системы не работали, закрытыми были все герметические клапаны на вытяжных системах, клапаны избыточного давления тамбуров входов также находились в закрытом положении. Проведенные замеры величины подпора воздуха в помещении ОКЗ при измерении должны были соответствовать нормативным величинам, указанным в [7, 10]. Целью создания в РФ нормативного документа в соответствии с [10] было максимальное повышение уровня безопасности людей находящихся в ЗС ГО в соответствии с требованиями европейских норматив- ных документов к эксплуатационным характеристикам и методам оценки ЗС ГО. Поэтому в соответствии с документом [7] в ЗС ГО при их непосредственном применении по назначению необходимо проведение контроля газового состава воздуха, микроклимата и инженернотехнического оборудования.

В табл. 3 показаны значения параметров контролируемых в ЗС ГО. В соответствии с «Правилами эксплуатации защитных сооружений гражданской обороны» [9] проводилось построение эталонных таблиц. Методика построения эталонных таблиц включала следующие этапы:

1. Создание эталонной модели имеющей общее с искомым решением обозначенной проблемы. По своему характеру эталонная модель являлась обобщённым представлением процессов протекающих в изучаемом оборудовании предназначенным для очистки воздуха.

Таблица 3

Перечень параметров, контролируемых в ЗС ГО

\begin{tabular}{|c|c|c|c|}
\hline $\begin{array}{c}\text { Наименование } \\
\text { параметров }\end{array}$ & $\begin{array}{l}\text { Значение параме- } \\
\text { тров }\end{array}$ & Средства измерения & Примечание \\
\hline \multicolumn{4}{|c|}{ I. Параметры газового состава воздуха } \\
\hline \multicolumn{4}{|c|}{ Содержание в воздухе: } \\
\hline кислорода & не менее $14 \%$ & $\begin{array}{l}\text { МН-5130, КГС-К, } \\
\text { ПГА-КМ, ГХЛ-1 }\end{array}$ & $\begin{array}{l}\text { предельно допустимое значение } \\
\text { параметра }\end{array}$ \\
\hline $\begin{array}{l}\text { двуокиси угле- } \\
\text { рода }\end{array}$ & не более $4,0 \%$ & КГС-ОУ, ГС-СОМ, ГХЛ-1 & $\begin{array}{l}\text { предельно допустимое значение } \\
\text { параметра }\end{array}$ \\
\hline окиси углерода & не более 100 мг/м & $\begin{array}{l}\text { ТП2221, КГС-ДУ, } \\
\text { КГП-ДУ, ГХЛ-1 }\end{array}$ & $\begin{array}{l}\text { предельно допустимое значение } \\
\text { параметра }\end{array}$ \\
\hline метана & не более 300 мг/м & KAM-IV-3, OA-2309M & $\begin{array}{l}\text { рекомендованное значение } \\
\text { параметра }\end{array}$ \\
\hline пыли & не более $10 \mathrm{мг/м}$ & Лаза-1 & $\begin{array}{l}\text { предельно допустимое значение } \\
\text { параметра }\end{array}$ \\
\hline \multicolumn{4}{|c|}{ II. Параметры микроклимата } \\
\hline $\begin{array}{l}\text { температура воз- } \\
\text { духа }\end{array}$ & не более $32^{\circ} \mathrm{C}$ & $\begin{array}{l}\text { TM-4, TM-8, СП-8, M-34, } \\
\text { MB-4M }\end{array}$ & $\begin{array}{l}\text { предельно допустимое значение } \\
\text { параметра }\end{array}$ \\
\hline $\begin{array}{l}\text { относительная } \\
\text { влажность воз- } \\
\text { духа }\end{array}$ & $\begin{array}{l}\text { не менее } 30 \% \\
\text { не более } 90 \%\end{array}$ & $\begin{array}{l}\text { M-19, CKB, M-34, } \\
\text { MB-4M }\end{array}$ & $\begin{array}{l}\text { предельно допустимое значение } \\
\text { параметра }\end{array}$ \\
\hline $\begin{array}{l}\text { скорость движе- } \\
\text { ния воздуха }\end{array}$ & $\begin{array}{l}\text { не более } 4 \mathrm{~m} / \mathrm{c} \\
(\text { не более } 8 \mathrm{~m} / \mathrm{c})\end{array}$ & $\mathrm{MC}-13, \mathrm{ACO}-3$ & $\begin{array}{l}\text { рекомендованное значение } \\
\text { параметра (в скобках - для } \\
\text { системы вентиляции) }\end{array}$ \\
\hline \multicolumn{4}{|c|}{ III. Параметры инженерно-технического оборудования } \\
\hline $\begin{array}{l}\text { избыточное } \\
\text { давление }\end{array}$ & не менее 20 Па & $\begin{array}{l}\text { ТНЖ-Н, ТНМП-52, } \\
\text { НМП-52 }\end{array}$ & $\begin{array}{l}\text { минимально допустимое значе- } \\
\text { ние параметра }\end{array}$ \\
\hline $\begin{array}{l}\text { сопротивление } \\
\text { фильтра }\end{array}$ & не более 1000 Па & $\begin{array}{l}\text { ТНМП-100, НМП-100, } \\
\text { ДНМП-100 }\end{array}$ & паспортные данные изделия \\
\hline
\end{tabular}

П р и м еч а н и я : Рекомендуемые средства измерения являются взаимозаменяемыми для каждого измеряемого параметра. 
2. При создании эталонной таблицы - были использованы комбинации взаимодействующих элементов, организованных для достижения цели исследования в которой основными исследуемыми ЗСГО ОКЗ являлись фильтры-поглотители для очистки воздуха и средства регенерации воздуха.

3. Для достижения цели проводилось построение эталонных таблиц. При построении эталонных таблиц руководствовались «Правилами эксплуатации защитных сооружений гражданской обороны...» [9].

4. Нумерация строк и столбцов таблицы при большом их числе проводилась $(1,2,3, \ldots$ А, Б, В и т. д.).

5. Все клетки таблиц заполнялись, при отсутствии данных использовались следующие условные обозначения:

«-» (тире) - явления отсутствуют;

«...» (многоточие) - явление существует, но сведений о нем нет;

«×» (крестик) - клетка не подлежит заполнению;

«0» (нуль) - явление существует, но значение его показателя менее половины единицы, принятой при округлении.

6. Таблицы сопровождались примечаниями, в которых указывались источники данных, более подробно раскрывалось содержание исследуемых показателей, и приводились другие пояснения.

При построении ситуационных таблиц обращалось внимание на ситуации, имеющие место в документах $[7,11]$. На основании сравнения эталонных и ситуационных таблиц, было, выявлено насколько удовлетворяют эталонные и ситуационные таблицы требованиям к параметрам работы вентиляционных систем ОКЗ, фильтровпоглотителей для очистки воздуха и средств регенерации воздуха.

В работе апробирована возможность построения функций принадлежности лингвистических переменных, это основано на возможности применения самих лингвистических переменных при описании исследуемых характеристик анализируемых в работе с помощью нечетких множеств по степени их проявления, где:

1. Нечеткая переменная характеризовалась тройкой признаков $(a, X, A)$,

где $a$ - наименование переменной;
$X$ - универсальное множество (область определения $a$ );

$A$ - нечеткое множество на $X$, описывающее ограничения (т. е. $m A(x))$ на значения нечеткой переменной а.

2. Лингвистическая переменная (ЛП) представляла собой следующие ее значения $(b, T, X, G, M)$,

где $b$ - наименование ЛП;

$T$ - множество ее значений (терммножество ЛП), представляющее собой наименования нечетких переменных, областью определения каждой из которых являлось множество $X$;

$G$ - синтаксическая процедура, позволяющая оперировать элементами терм-множества $T$ и генерировать новые термы (значения);

$M$ - семантическая процедура, позволяющая превратить каждое новое значение ЛП, образуемое $G$, в нечеткую переменную, т. е. сформировать соответствующее нечеткое множество.

На основании проведенного математического моделирования, построения эталонных и ситуационных таблиц можно сказать следующее, что функция принадлежности ЛП - применена в работе как набор множеств ее значений (терммножество), представляющих собой наименования нечетких переменных, областью определения каждой из которых явилось множество значений $X$.

Формирование ЛП включало следующие этапы:

1. Определение множества термов ЛП и его упорядочение.

2. Построение числовой области определения ЛП.

3. Построение функций принадлежности для каждого терма ЛП.

Для того, чтобы иметь полную картину результатов моделирования использовалась возможность прибегнуть к функции нечеткого множества, которая стала обобщением обычных множеств, где отказываются от бинарного характера этой функции и предполагается, что функция нечеткого множества может принимать любые значения из отрезка [от 0 до 1] [13, 14].

В заключение следует сказать, что для того чтобы применить математическое моделирование при изучении характеристик защитных сооружений гражданской обороны предназначенных для защиты населения при военных 
действиях, вследствие этих действий, при чрезвычайных ситуациях природного и техногенного характера в работе рассмотрены основные правовые и нормативно-технические документы регламентирующие деятельность такого рода объектов. Логический вывод в исследованиях защитных сооружений гражданской обороны, где объектом ис- следования были фильтры-поглотители для очистки воздуха и средства регенерации воздуха осуществлялся поэтапно с составлением научного анализа математической модели, данных эталонных и ситуационных таблиц и возможности применения лингвистических переменных с помощью нечетких множеств по степени их проявления.

Библиографический список

1. Федеральный закон от 12.02.1998 г. №28-Ф3 «О гражданской обороне».

2. Федеральный закон от 21.12.1994 г. №68-Ф3 «О защите населения и территорий от чрезвычайных ситуаций природного и техногенного характера».

3. Военная доктрина Российской Федерации, утверждена Президентом Российской Федерации 25. 12. 2014 г. №Пр-2976.

4. Основы единой государственной политики Российской Федерации в области гражданской обороны на период до 2020 года (утв. Президентом Российской Федерации 03. 11.2011 г. пр-2613).

5. Федеральный закон от 12.02.1998 г. №28-Ф3 «О Гражданской обороне».

6. Постановление Правительства Российской Федерации от 26.11.2007 г. № 804 «Об утверждении Положения о Гражданской обороне в Российской Федерации».

7. Приемка в эксплуатацию законченных строительством защитных сооружений и их содержание в мирное время СНиП 3.01.09-84.

8. Постановление Правительства Российской Федерации от 29.11.1999 г. № 1309 «О порядке создания убежищ и иных объектов гражданской обороны».

9. Приказ Министерства Российской Федерации по делам Гражданской обороны, чрезвычайным ситуациям и ликвидации последствий стихийных бедствий от 15.12.2002 №583 об утверждении Правил эксплуатации защитных сооружений гражданской обороны (с изменениями и дополнениями на 26 июня 2018 г.).

10. Федеральный закон от 30 декабря 2009 г. № 384-Ф3 «Технический регламент о безопасности зданий и сооружений».

11. СНиП 2.01.51-90 «Инженерно-технические мероприятия гражданской обороны».

12. Гражданская оборона / под общ. ред. В.А. Пучкова; МЧС России. - М.: ФГБУ ВНИИ ГОЧС (ФЦ), 2015. - 392 c.

13. Заде Л. Понятие лингвистической переменной и ее применение к принятию приближенных решений. - М.: Мир, 1976. - 165 с.

14. Орловский С.А. Проблемы принятия решений при нечеткой исходной информации. - М.: Наука, 1981. - 208 с.

15. Анализ служебной деятельности Главного управления МЧС России по г. Санкт-Петербургу за 2015 год [Электронный ресурс] // Сайт Главного управления МЧС России по г. Санкт-Петербургу http://78.mchs.gov.ru/document/3434372. 